\title{
Preventive gynecology: attitude and practice among gynecologists of Central Kerala
}

\author{
Radha K. R.*, Reena R. P., Jacob K. J.
}

Department of Obstetrics and Gynecology, Government Medical College, Thrissur, Kerala, India

Received: 09 May 2017

Accepted: 15 May 2017

\section{*Correspondence:}

Dr. Radha K. R.,

E-mail: dr.radhakr@rocketmail.com

Copyright: (C) the author(s), publisher and licensee Medip Academy. This is an open-access article distributed under the terms of the Creative Commons Attribution Non-Commercial License, which permits unrestricted non-commercial use, distribution, and reproduction in any medium, provided the original work is properly cited.

\section{ABSTRACT}

Background: Carcinoma breast and carcinoma cervix are leading causes for cancer deaths in India. However, they get detected only in late stages of the disease. Preventive measures and early detection of disease will decrease the burden from these cancers. We evaluated the strategies followed by practising gynecologists of Central Kerala to reduce this burden.

Methods: A survey was conducted among 270 practising gynecologists of Central Kerala, using a questionnaire. This evaluated implementation of screening and preventive measures used by them for self-protection as well as for the women seeking their services. Their attitude regarding HPV vaccine as a preventive measure was also noted.

Results: Pap smear was done by only 84(32.8\%) out of 256 gynecologists or their spouses. Routine Pap smear was recommended by $60.5 \%$ of private practitioners and $84 \%$ of government practitioners. Counselling regarding the HPV vaccine was offered to young women by $37.8 \%$ of gynecologists only. Use of HPV vaccine for their daughters was also quite infrequent $(24.1 \%)$.

Conclusions: The utilization of existing preventive strategies and measures for early detection of premalignant and malignant lesions is far from optimum. There is a need to step up in service training and continuing medical education for health care personnel in this direction.

Keywords: Cervical cancer, HPV vaccine, Mammography, Pap smear

\section{INTRODUCTION}

Carcinoma breast and carcinoma cervix are the most common malignancies in women. There were 3, 26,300 deaths due to cancer among women in India in 2014. Among them, $20.7 \%$ deaths were due to cancer cervix, while $21 \%$ were due to breast malignancy. ${ }^{1}$ In India, most cases of cancer cervix get detected in an advanced stage of the illness. Factors like illiteracy, lack of access to health care, poverty and absence of symptoms often lead to late detection and poor outcome with treatment. ${ }^{2}$

HPV vaccination was introduced for primary prevention of carcinoma cervix following the attribution of High risk HPV as the causative agent. ${ }^{3,4}$ Screening for premalignant lesions using Pap smear and HPV DNA are now recommended as methods for secondary prevention. ${ }^{5}$ There are about 444.7 million females aged 15 years or more in India. ${ }^{6}$ Systematic screening of such a large population is not easy or feasible. Moreover, the costs for this will be very high.

Vaccinating girls between 9 and 12 years may offer an alternative option to decrease this burden. The use of HPV Vaccine has been approved by the Drug Controller of India. Two immunization programmes were introduced in 2007. One was by PATH (Programme for Appropriate Technology in Health, New Delhi) and the other by the state governments under ICMR (Indian Council of Medical Research, New Delhi). These were 
later suspended due to reports of adverse reactions to the vaccine, which later proved to be baseless. ${ }^{7}$

Kerala has a high female literacy rate and an immunisation coverage that exceeds $90 \%$ for children. However, the morbidity and mortality from carcinoma cervix remains unacceptably high. Most cases do not get identified early. A vast majority $(78 \%)$ of cases of carcinoma cervix on treatment from our centre had sought help only in the advanced stages of the disease. Moreover, these subjects were not aware of the availability of screening and vaccination programs for prevention of carcinoma cervix. ${ }^{8}$ Scaling up of public awareness about the usefulness and availability of these services thus becomes very important. Without sustained efforts at raising public awareness, these services will remain underutilized. Doctors, especially gynaecologists, can contribute a great deal, in raising the level of public awareness. Favourable parental attitude and opportunities for discussion and clarification of doubts about the HPV vaccine with care providers are crucial for its acceptance. $^{9}$

We decided to evaluate the prevailing attitude and practice of gynaecologists in preventing malignancies especially carcinoma cervix. We also wanted to know about the utilization status of the vaccine and the opinion of gynaecologists regarding its use.

\section{METHODS}

A pilot study was conducted among practising gynaecologists and using a prepared questionnaire which incorporated the utilization of gynaecological screening procedures and counselling regarding the HPV vaccine. Only $30 \%$ of the gynaecologists or the spouses of male gynaecologists had undergone Pap smear. We expected a response rate of $50 \%$ and estimated the required sample size to be 350 for the survey.

In present study, a cross sectional design was used. We designed a questionnaire to collect information for the study. Gynaecologists registered in the Obstetrics and Gynaecological Societies and /or working in tertiary care centres of Central Kerala were approached. The study questionnaire was either personally handed over or posted to 400 practising gynaecologists. The details sought by the questionnaire included information, whether the person (female gynaecologist or the spouse of male gynaecologist) had undergone a pelvic examination, ultrasonography of abdomen and pelvis, HPV DNA screening, Pap smear and mammography. It also enquired whether the practitioner was offering preventive measures for carcinoma cervix. The queries included asking for Pap smear test, counselling regarding HPV vaccine for adolescent girls and administration of the vaccine to their own daughters.
The completed questionnaires were collected. The data was compiled, analyzed and results were expressed in means and percentages.

\section{RESULTS}

The response rate for the survey was $67.5 \%$ with the participation of 270 gynaecologists. This included 20 male gynaecologists. Two of the male gynaecologists and 12 of the 250 female gynaecologists were unmarried. Nine female gynaecologists were less than 30 years of age. Most of the gynaecologists were experienced practitioners while only thirty-three of them had been in practice for less than 5 years. Majority of them (72\%) were from the private sector.

Table 1: Details of screening undergone by female gynaecologists and spouses of male gynaecologists.

\begin{tabular}{|l|l|l|}
\hline Test & $\begin{array}{l}\text { Spouses of male } \\
\text { gynaecologists } \\
(18)\end{array}$ & $\begin{array}{l}\text { Female } \\
\text { gynaecologists } \\
(250 \text { includes } 12 \\
\text { unmarried) }\end{array}$ \\
\hline Pap smear & $8(44.4 \%)$ & $\begin{array}{l}76(\text { out of } 238) \\
(31.9 \%)\end{array}$ \\
\hline $\begin{array}{l}\text { HPV-DNA } \\
\text { test }\end{array}$ & 0 & $\begin{array}{l}6(\text { out of } 238) \\
(2.5 \%)\end{array}$ \\
\hline Mammography & $6(33.3 \%)$ & $40(16 \%)$ \\
\hline $\begin{array}{l}\text { Gynaecological } \\
\text { examination }\end{array}$ & $6(33.3 \%)$ & $77(30.8 \%)$ \\
\hline $\begin{array}{l}\text { Ultrasound } \\
\text { examination }\end{array}$ & $5(27.8 \%)$ & $131(52.4 \%)$ \\
\hline No tests done & $5(27.8 \%)$ & $64(25.6 \%)$ \\
\hline Not applicable & $4(22.2 \%)$ & $3(1.2 \%)$ \\
\hline
\end{tabular}

\section{Self-protection}

There were 238 female gynaecologists and 18 women married to male gynaecologists among them, who were eligible for getting a Pap smear and HPV-DNA testing done. The screening modalities carried out by the gynaecologists are given in Table 1.

Routine Pap smear was offered to the public by 181 (67\%) out of 270 gynaecologists. Details regarding the use of Pap smear among gynaecologists working in private hospitals and government run hospitals are given in Table 2.

HPV counselling was offered to adolescents, preadolescent girls and their parents by $83(42.6 \%)$ of the private practitioners and $19(25.3 \%)$ of the government practitioners, 159 of the 270 gynaecologists have daughters. Among them, 87 were in the age group eligible for being vaccinated. Only 21 (24.1\%) had vaccinated their daughters. The reasons for not counselling adolescents and for not vaccinating their own daughters are given in Table 3. 
Table 2: Pattern of pap smear screening offered by gynaecologists.

\begin{tabular}{|lll|}
\hline Pap smear & $\begin{array}{l}\text { Private } \\
\text { practitioners } \\
(\mathrm{N}=195)\end{array}$ & $\begin{array}{l}\text { Government } \\
\text { practitioners } \\
(\mathrm{N}=75)\end{array}$ \\
\hline Routine & $118(60.5 \%)$ & $63(84 \%)$ \\
\hline Indicated & $73(37.4 \%)$ & $12(16 \%)$ \\
\hline $\begin{array}{l}\text { Not done (indicated and } \\
\text { routine) }\end{array}$ & $4(2.1 \%)$ & 0 \\
\hline Pap smear deferred & $34(17.4 \%)$ & $8(10.7 \%)$ \\
\hline $\begin{array}{l}\text { Bleeding } \\
\text { Discharge }\end{array}$ & $10(5.1 \%)$ & 0 \\
\hline High risk & $11(5.6 \%)$ & 0 \\
\hline
\end{tabular}

Table 3: HPV vaccine counselling/administration.

\begin{tabular}{|lll|}
\hline HIPV & $\begin{array}{l}\text { Counselling } \\
\text { offered to } \\
\text { adolescent and } \\
\text { preadolescent girls } \\
\mathbf{( N = 2 7 0 )}\end{array}$ & $\begin{array}{l}\text { Vaccine given to } \\
\text { own daughters } \\
\text { eligible for } \\
\text { vaccination } \\
\text { (N=87) }\end{array}$ \\
\hline Yes & $102(37.8)$ & $21(24.1 \%)$ \\
\hline No & $168(62.2 \%)$ & $66(75.9 \%)$ \\
\hline Reasons & $\begin{array}{l}\text { For not } \\
\text { counselling (168) }\end{array}$ & $\begin{array}{l}\text { For not } \\
\text { vaccinating }(\mathbf{6 6})\end{array}$ \\
\hline $\begin{array}{l}\text { Not thought } \\
\text { of }\end{array}$ & $80(47.6 \%)$ & $40(60.6 \%)$ \\
\hline $\begin{array}{l}\text { Benefit } \\
\text { uncertain }\end{array}$ & $49(29.2 \%)$ & $19(28.8 \%)$ \\
\hline Expensive & $35(20.8 \%)$ & $2(3 \%)$ \\
\hline Unnecessary & $4(2.4 \%)$ & $5(7.6 \%)$ \\
\hline
\end{tabular}

\section{DISCUSSION}

Present study found that female gynaecologists and the wives of male gynaecologists tend to ignore the need to undergo screening procedures for early detection of malignancy. Their responses indicate that their efforts towards prevention are less than adequate. This may be the case with other health professionals too. It appears that awareness and practice are not directly linked. It could also mean that the practice of what is desirable can also be determined by the prevailing pattern of utilization among the rest in the community. We also noted that many gynaecologists failed to offer HPV vaccination to clients in their practice. This clearly points towards the need to have an action oriented understanding about several aspects of preventive gynaecology among practising health care personnel, including the specialists. Health professionals and their health related behaviour can influence the behaviour of others. We need to set examples by actively promoting evidence informed practice; be it personal health care or provision of clinical services.

Of the 238 female gynaecologists who should have had a Pap smear, 162 (68.1\%) did not have the test done. There were 117 female gynaecologists aged 50 years or more, but only $31(26.5 \%)$ had undergone mammography at least once. The American Cancer Society recommends annual screening by mammography after 45 years in average risk women. The U.S. Preventive Task Force recommends biennial mammography after the age of $50 .{ }^{10}$ Even though there are different guidelines regarding the age of initiation of mammography and the frequency of undergoing the test; it continues to be recommended as a screening tool for early detection of carcinoma breast especially after the age of 50. Most Well Woman Clinics worldwide recommend annual general health check-ups including gynaecological examination and preventive health care measures.

Pelvic ultrasound examination was done in $131(52.4 \%)$. None of the screening tests were done in 64 (25.6\%). Among those who were subject to screening 57 (30.6\%) did some or all tests as part of work up for a diagnostic or therapeutic procedure. Three female gynaecologists who were unmarried, felt they did not require any of the screening tests to be done. Celibacy may be a protective factor against developing cervical cancer, but nulliparity is a risk factor for ovarian, endometrial and breast cancer.

Seventy-seven (30.8\%) gynaecologists had never undergone a gynaecological examination. Doctors often do not follow current preventive health guidelines for their own physical health. ${ }^{11}$ Present study emphasises this fact. However, wives of male gynaecologists were more keen on screening than the female gynaecologists in undertaking preventive strategies. A study from Kerala found that only $6.9 \%$ of 809 women had undergone Pap smear tests though three - fourths of them did know about the availability of Pap smear test for early detection of cervical cancer. ${ }^{12}$ Screening is often opportunistic or carried out after the onset of symptoms. While screening health provider gets an opportunity to visualise the cervix which may also help to downstage carcinoma cervix. This is important in our country where a proper screening programme is not in place.

Routine Pap smear was offered by only $67 \%$ of gynaecologists $(60.5 \%$ in private sector, $84 \%$ in government sector) to women who sought their services. We found a small minority (1.5\%) gynaecologists not offering Pap smear to women routinely or even in the presence of indications. Though $31.5 \%$ of the gynaecologists claimed to recommend Pap smear to symptomatic women it appeared that symptoms like bleeding $(46 \%)$ or discharge $(13.7 \%)$ per vaginum were deterrents for carrying out this investigation. This may inadvertently lead to delay in detection of cervical lesions. An opportunity for screening may be lost by this postponement as the woman may not return for further evaluation.

WHO recommends Pap smear to be taken at least once between the ages of 35 and $54 .{ }^{13}$ Most common and time tested method for screening for pre-malignant lesions of cervix is pap smear, and it was effective in reducing the incidence of invasive disease by $50 \%$ to $60 \%$ in countries with a well organised screening program. ${ }^{14}$ There is a 
need to improve use of Pap smear screening by the service providers working in public and private hospitals.

Vaccine preventable HPV subtypes 16 and 18 are responsible for $70 \%$ of cervical cancer. ${ }^{3,4} \mathrm{HPV}$ can be detected in $40 \%$ of vulval cancers, $70 \%$ of vaginal cancers, $50 \%$ of penile cancers, $85 \%$ of anal cancers, $35 \%$ of oropharyngeal cancers and $25 \%$ of other oral cavity cancers. ${ }^{3}$ HPV related cancers are preventable by vaccination. HPV vaccine has shown to be effective in decreasing the incidence of premalignant lesions by 70 to $90 \% .^{15,16}$

Advisory Committee on Immunisation Practices (ACIP) recommends routine vaccination with HPV4 or HPV2 for females aged 11 or 12 years and with HPV4 for males aged 11 or 12 years. For those who were not vaccinated earlier, ACIP recommends vaccination for females aged 13 through 26 years and for males aged 13 through 21 years. The committee also recommends vaccination of homosexual men and immunocompromised persons (including those with HIV infection) through age 26 years if not previously vaccinated. ${ }^{17}$

Counselling for HPV vaccine was offered only by $37.8 \%$ of gynaecologists. Therefore, a large number of gynaecologists $(62.2 \%)$ were not engaging prepubertal girls, the potential beneficiaries of advice, regarding the HPV vaccine. The reasons for not providing counselling services included factors like failure to consider the option of vaccinating $(47.6 \%)$, uncertainty about its benefits (29.2\%), vaccine was expensive (20.8\%) and unnecessary $(2.4 \%)$.

159 gynaecologists had daughters. Among them, 87 had daughters who were eligible for HPV vaccination. Only $24 \%$ (21) were vaccinated against HPV infection. Hence $76 \%$ of the gynaecologists did not vaccinate their own daughters who were in the eligible age group. Among them $60.6 \%$ (40) failed to consider the option of vaccinating, $28.8 \%$ (19) were not sure of the benefits, $7.6 \%$ (5) thought it was unnecessary and for 3\% (2) it was expensive.

Vaccinating girls between the ages of 14 and 19 has been found to reduce the prevalence of vaccine type HPV infection (HPV type 6, 11, 16, 18) from $11.5 \%$ in 2003 2006 to $5.15 \%$ in $2007-2010$ in the United States of America. ${ }^{18}$ Vaccinating 12-year-old girls (70\% coverage) with bivalent /quadrivalent vaccines is predicted to reduce Cervical Intraepithelial Neoplasia (CIN) 2 and 3, cervical squamous cell carcinoma and anogenital warts substantially over 70 years. The nonavalent vaccine may further reduce precancerous lesions and cervical malignancy. ${ }^{19}$ It has been found that when young women, not previously infected with HPV 16 and 18 and adolescents before sexual debut, were vaccinated with HPV vaccine, the occurrence of high grade cervical abnormalities was significantly reduced. ${ }^{14,16}$
HPV vaccination has been included in more than 80 countries in their National Immunisation programmes according to GAVC (GLOBAL alliance for vaccine safety, WHO). The vaccine is considered safe and no serious adverse effects have been reported. ${ }^{20}$ However, vaccination coverage was only $1 \%$ among females aged between 10 and 20 years in the low-income countries, when compared to $33.6 \%$ for the same age group in the developed nations. ${ }^{20}$

A large proportion of gynaecologists failed to offer HPV vaccination either due to ignorance of its benefits or their misconceptions regarding the vaccine. This highlights the need for improving awareness regarding several aspects of preventive gynaecology for practising health care personnel. Regular upgrading of knowledge and awareness of newer developments in this field is a must to promote optimum utilisation of these services. There is a strong case for active dissemination of new knowledge. This knowledge should transform practices. We need evidence informed health care at the point of delivery. This will help the recipient to have better health outcomes. Scaling up of evidence informed health care by practitioners like gynaecologists can make a huge difference by reducing incidence of genital malignancies among women. We will then see a significant reduction in the morbidity and mortality due to carcinoma cervix.

\section{Limitations}

Socio-economical, cultural and facility based factors which may have influenced the utilization of services and adoption of preventive measures were not looked into.

\section{CONCLUSION}

Gynaecologists are well aware that HPV vaccine and regular cervical screening are the most effective ways of preventing cervical cancer. However, this is not reflected in their practice. Proper and effective utilization of available facilities would depend on creating better understanding and change in their outlook. Stepping up and strengthening of preventive health care services is essential to reduce the burden from cervical cancer and other gynaecological cancers.

\section{Funding: No funding sources \\ Conflict of interest: None declared}

Ethical approval: The study was approved by the Institutional Ethics Committee

\section{REFERENCES}

1. WHO Cancer country profile 2014 prepared by IACR. Available from: http://www.who.int/cancer/country-profiles/en/

2. Nandakumar A, Anantha N, Venugopal TC. Incidence, mortality and survival in cancer of the cervix in Bangalore, India. $\mathrm{Br} \mathrm{J}$ Cancer. 1995;71(6):1348-52. 
3. Grulich AE, Jin F, Conway EL, Stein AN, Hocking J. Cancers attributable to human papilloma virus infection. Sex Health. 2010;7(3):244-52.

4. de Sanjose S, Quint WG, Alemany L, Geraets DT, Klaustermeier JE, Lloveras B et al. Human papillomavirus genotype attribution in invasive cervical cancer: a retrospective cross-sectional worldwide study. Lancet Oncol. 2010;11:1048-5.

5. Sasieni P, Castanon A, Cuzick J. Effectiveness of cervical screening with age: population based case control study of prospectively recorded data. BMJ 2009;339:b2968.

6. Central Intelligence Agency - The World Factbook. Available from: https://www.cia.gov/library/publications/the-worldfactbook/

7. Final Report of the Committee appointed by the Govt. of India, vide notification No. V.25011/160/2010-HR dated 15th April, 2010, to enquire into Alleged irregularities in the conduct of studies using Human Papilloma Virus (HPV) vaccine by PATH in India February 15, 2011.

8. Radha KR, Reena RP. Factors associated with delayed reporting of invasive carcinoma Obstetrics cervix in a rural tertiary care centre. J Obstet Gynaecol India. 2016;66(5):S417-S421.

9. McRee AL, Gilkey MB, Dempsey AF. HPV vaccine hesitancy: findings from a statewide survey of health care providers. J Pediatr Health Care. 2014;28(6):541-9.

10. Screening for Breast Cancer: U.S. Preventive Services Task Force Recommendation Statement. Ann Intern Med. 2009;151:716-26.

11. Kay M, Mitchell G, Del Mar C. Doctors do not look after their own physical health. Med J Aust. 2004;181(7):368-70.

12. Aswathy S, Quereshi MA, Kurian B, Leelamoni K. Cervical cancer screening: Current knowledge and practice among women in a rural population of Kerala, India. Indian J Med Res. 2012;136(2):20510.

13. Catarino R, Petignat P, Dongui G, Vassilakos P. Cervical cancer screening in developing countries at a crossroad: Emerging technologies and policy choices. World J Clin Oncol. 2015;6:281-90.
14. Sasieni P, Castanon A, Cuzick J. Effectiveness of cervical screening with age: population based casecontrol study of prospectively recorded data. BMJ. 2009;339:b2968.

15. Future II study group, Quadrivalent vaccine against Human Papilloma virus to prevent high grade cervical lesion. New Engl J Med. 2007;356(19):1915-27.

16. Apter D, Wheeler CM, Paavonen J, Castellsagué X, Garland SM, Skinner SR, Naud P, Salmerón J, Chow SN, Kitchener HC, Teixeira JC. Efficacy of human papillomavirus 16 and 18 (HPV-16/18) AS04adjuvanted vaccine against cervical infection and precancer in young women: final event-driven analysis of the randomized, double-blind PATRICIA trial. Clini Vaccine Immunol. 2015;22(4):361-73.

17. Markowitz LE, Dunne EF, Saraiya M, Chesson HW, Curtis CR, Gee $\mathrm{J}$ et al. Human Papillomavirus Vaccination Recommendations of the Advisory Committee on Immunization Practices (ACIP). MMWR Recomm Reports. 2014;63(1):1-30.

18. Markowitz LE, Hariri S, Lin C, Dunne EF, Steinau M, McQuillan $G$ et al. Unger Reduction in human papillomavirus (HPV) prevalence among young women following HPV vaccine introduction in the United States, National Health and Nutrition Examination Surveys, 2003-2010. J Infect Dis. 2013;208(3):385-93.

19. Van de Velde N, Boily MC, Drolet M, Franco EL, Mayrand $\mathrm{MH}$, Kliewer EV et al. Population-level impact of the bivalent, quadrivalent, and nonavalent human papillomavirus vaccines: a model-based analysis. J Natl Cancer Inst. 2012;104:1712-23.

20. WHO /Global Advisory Committee on Vaccine safety Statement on Safety of HPV vaccines 17 December 2015.

Cite this article as: Radha KR, Reena RP, Jacob KJ. Preventive gynaecology: attitude and practice among gynecologists of Central Kerala. Int J Reprod Contracept Obstet Gynecol 2017;6:2318-22. 